ARTICLE

\title{
Surface chelation of cesium halide perovskite by dithiocarbamate for efficient and stable solar cells
}

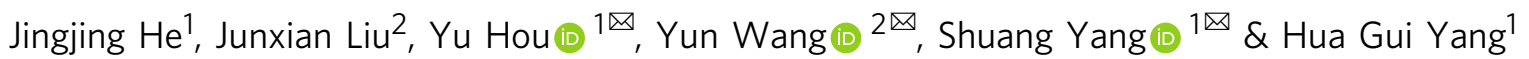

Surface engineering has been shown critical for the success of perovskite solar cells by passivating the surface enriched defects and mobile species. The discovery of surface modulators with superior interaction strength to perovskite is of paramount importance since they can retain reliable passivation under various environments. Here, we report a chelation strategy for surface engineering of $\mathrm{CsPbl}_{2} \mathrm{Br}$ perovskite, in which dithiocarbamate molecules can be coordinate to surface $\mathrm{Pb}$ sites via strong bidentate chelating bonding. Such chelated $\mathrm{CsPb}_{2} \mathrm{Br}$ perovskite can realize excellent passivation of surface under-coordinated defects, reaching a champion power conversion efficiency of $17.03 \%$ and an open-circuit voltage of $1.37 \mathrm{~V}$ of $\mathrm{CsPb}_{2} \mathrm{Br}$ solar cells. More importantly, our chelation strategy enabled excellent device stability by maintaining $98 \%$ of their initial efficiency for over $1400 \mathrm{~h}$ in ambient condition. Our findings provide scientific insights on the surface engineering of perovskite that can facilitate the further development and application of perovskite optoelectronics.

\footnotetext{
${ }^{1}$ Key Laboratory for Ultrafine Materials of Ministry of Education, Shanghai Engineering Research Center of Hierarchical Nanomaterials, School of Materials Science and Engineering, East China University of Science and Technology, 130 Meilong Road, 200237 Shanghai, China. ${ }^{2}$ Centre for Clean Environment and Energy, School of Environment and Science, Gold Coast Campus, Griffith University, Brisbane, QLD 4222, Australia. ${ }^{\varpi_{\text {email: }}}$ yhou@ecust.edu.cn; yun.wang@griffith.edu.au; syang@ecust.edu.cn
} 
ead halide perovskite-based solar cells are one of the most promising photovoltaic technologies benefited from its high efficiency, low cost, and solution processibility ${ }^{1-6}$. Unfortunately, the hybrid perovskites are susceptible to be degraded under thermal condition due to the volatility nature of the organic cations ${ }^{7-9}$. Replacing the volatile organic cations with inorganic $\mathrm{Cs}^{+}$can offer intrinsically thermal stable perovskite phase over $400^{\circ} \mathrm{C}$ with a tunable bandgap between $1.73 \mathrm{eV}$ of $\mathrm{CsPbI}_{3}$ to $2.25 \mathrm{eV}$ of $\mathrm{CsPbBr}_{3}{ }^{10,11}$. Among various cesium halide perovskites, $\mathrm{CsPb}_{2} \mathrm{Br}$ perovskite is considered to be a good candidate for the high efficiency and stable all-inorganic perovskite solar cells (PSCs) due to its reasonable Goldschmidt tolerance factor and the lower phase transition temperature with band gaps between 1.82 and $1.92 \mathrm{eV}^{12,13}$. Currently, the power conversion efficiency (PCE) of over $16 \%$ has been achieved for the $\mathrm{CsPbI}_{2} \mathrm{Br}$ solar cells, but their moisture and light instability is still an outstanding issue that remained to be solved ${ }^{14,15}$.

The degradation of perovskites has been identified to be initialized from the surfaces and/or grain boundaries, where are enriched with undercoordinated ions or mobile species ${ }^{16-18}$. These defective surfaces also introduce electronic trap states that act as fast channels for the nonradiative charge recombination ${ }^{19}$. Therefore, numerous studies have highlighted the significance of the passivation of surface defects and grain boundaries for achieving efficient and stable PSCs ${ }^{20-25}$. For example, fullerene and its derivatives can accept one electron from Lewis base type defects to passivate the perovskite surfaces in early studies ${ }^{26,27}$. Lewis bases, such as $\pi$-conjugated $6 \mathrm{TIC}-4 \mathrm{~F}$ and theophylline molecules, have been employed to not only passivate the uncoordinated surface of the perovskite, but also better align the interfacial energy levels ${ }^{15,28}$. Most recently, oxysalts have been reported as surface inorganic passivation layers that can suppress ion migration and enhance the device stability by the merit of strong primary ionic bonding between lead cations of perovskite and sulfate anions ${ }^{29}$. In principle, the reliable and stable surface passivation for perovskites can be achieved through the formation of the strong chemical bond after passivation since its dissociation becomes difficult under various environmental stimuli. Among various bonding types, the chelation, that is embodied by a special bonding mode of polydentate molecules to central metal ions, can enable enhanced affinity to the perovskite surface than that of conventional nonchelating (monodentate) ligands ${ }^{30,31}$.

In this paper, we introduce the diethyldithiocarbamate (DDTC) molecule as a chelating agent for the surface engineering of $\mathrm{CsPbI}_{2} \mathrm{Br}$ perovskite. It was found that DDTC molecule strongly coordinates to surface $\mathrm{Pb}$ cation of perovskite via a bidentate chelating bonding. Such chelating structure enabled excellent and persistent passivation of surface defects of $\mathrm{CsPbI}_{2} \mathrm{Br}$ perovskite, generating significantly enhanced efficiency of $17.02 \%$ for $\mathrm{CsPb}_{2} \mathrm{Br}$ solar cells as well as increased humidity and irradiation stability.

\section{Results}

Surface chelation of cesium halide perovskite. Figure 1a shows the optimized $\mathrm{CsPbI}_{2} \mathrm{Br}$ (001) surface associated to lead diethyldithiocarbamate $\left(\mathrm{Pb}(\mathrm{DDTC})_{2}\right)$ molecule, in which two $-\mathrm{NCS}_{2}$ groups anchor at central $\mathrm{Pb}$ ion with a bidentate configuration (see the atomic structure in Supplementary Fig. 1) 30,31 . The theoretical results based on the density functional theory (DFT) reveal that the $\mathrm{Pb}(\mathrm{DDTC})_{2}$ is adsorbed strongly on the surface with an adsorption energy of $-1.73 \mathrm{eV}$, which is much larger than that of the prevalent passivation molecules, such as ammoniums or carboxylic acids of about -0.4 and $-0.3 \mathrm{eV}^{32,33}$. As a further comparison, the adsorption energy of $\mathrm{H}_{2} \mathrm{O}$ on the $\mathrm{CsPbI}_{2} \mathrm{Br}(001)$ surface is calculated to be only about one-fifth of it $(-0.32 \mathrm{eV})$, which indicates the much weaker adsorption strength of water to perovskite (Supplementary Fig. 2a). In addition, positively charged $\mathrm{Pb}$ atom from $\mathrm{Pb}(\mathrm{DDTC})_{2}$ can be bonded strongly with surface $\mathrm{Br}$ and I atoms to neutralize the surface charge. However, the adsorption energy of $\mathrm{PbI}_{2}$ on $\mathrm{CsPb}_{2} \mathrm{Br}$ (001) surface was only $-1.11 \mathrm{eV}$ (Supplementary Fig. 2b), which suggests that the chelation between DDTC and surface undercoordinated $\mathrm{Pb}$ can further strengthen the adsorption. When DDTC anions bond to metal centers, they typically have serval coordination modes, such as isobidentate, anisobidentate, monodentate, triconnective (Supplementary Fig. 3) 31,34 . We notice that the DDTC molecules retain a bidentate chelating bonding to the center $\mathrm{Pb}$ cation in $\mathrm{Pb}(\mathrm{DDTC})_{2}$, yet offers extra interaction to another surface $\mathrm{Pb}$ atom, which causes the superior adsorption strength. Since the undercoordinated atoms in the pristine perovskite surface are typically the active sites for water adsorption and act as the electronic trap sites, our results suggest that the chelation of $\mathrm{CsPbI}_{2} \mathrm{Br}$ perovskite surfaces by using $\mathrm{Pb}$ (DDTC $)_{2}$ can be a promising approach to stabilize them under humid environment and enhance the overall performance.

According to the theoretical prediction, we employed $\mathrm{Pb}$ (DDTC $)_{2}$ as an additive in the perovskite precursor solution. The chelating agent is well dissolved in perovskite precursor solution, albeit insoluble in water (Supplementary Fig. 4). The addition of $\mathrm{Pb}(\mathrm{DDTC})_{2}$ with the concentration below $0.015 \mathrm{M}$ almost do not change the surface morphology and roughness of the $\mathrm{CsPbI}{ }_{2} \mathrm{Br}$ films as confirmed by the scanning electron microscopy (SEM) and the AFM images (Supplementary Figs. 5 and 6). X-ray diffraction (XRD) patterns in Supplementary Fig. 7 reveal the $\alpha$ phase perovskite structure of all samples without notable shift of diffraction peaks. This implies that the added DDTC molecules might be distributed at the grain boundaries of perovskite because of its large size ${ }^{26}$. Time-of-flight secondary-ion mass spectrometry (ToF-SIMS) further shows strong $\mathrm{H}^{-}$and $\mathrm{S}^{-}$signals at the perovskite surface and the perovskite/ $\mathrm{TiO}_{2}$ interface, while their intensities are less than a tenth of that at the interface throughout the perovskite film (Fig. 1b). The ToF-SIMS result presented here thus corroborates the enrichment of DDTC on the surface or interface of the polycrystalline perovskite film. In addition, the XPS results confirm the absence of $\mathrm{Sin}$ bare $\mathrm{TiO}_{2} / \mathrm{FTO}$ substrate (Supplementary Fig. 8). Therefore, the $\mathrm{S}^{-}$signal in the $\mathrm{TiO}_{2}$ and FTO region of ToF-SIMS spectra should be stemmed from DDTC molecules.

Fourier transform infrared (FTIR) spectra of $\mathrm{CsPbI}_{2} \mathrm{Br}$ perovskite with $\mathrm{Pb}(\mathrm{DDTC})_{2}$ (chelated $\mathrm{CsPbI}_{2} \mathrm{Br}$ perovskite) show similar characteristic absorption peaks with that of $\mathrm{Pb}(\mathrm{DDTC})_{2}$, which ascertains the existence of chelating agents in perovskite after thermal annealing at $160^{\circ} \mathrm{C}$ (Supplementary Fig. 9). The FTIR absorption bands at $830-1000 \mathrm{~cm}^{-1}, 1450-1580 \mathrm{~cm}^{-1}$, and $2850-3000 \mathrm{~cm}^{-1}$ regions primarily correspond to stretching vibration of $\mathrm{C}-\mathrm{S}, \mathrm{C}-\mathrm{N}$, and $\mathrm{C}-\mathrm{H}$ of DDTC molecules, respectively (Fig. 1c) ${ }^{34,35}$. The $\mathrm{C}-\mathrm{N}$ bond of DDTC molecules for both samples belongs to thioureide from with partial double bond character, as the $v(\mathrm{C}-\mathrm{N})$ locates between $v(\mathrm{C}=\mathrm{N})$ $\left(1640-1690 \mathrm{~cm}^{-1}\right)$ and $v(\mathrm{C}-\mathrm{N})$ bands $\left(1250-1350 \mathrm{~cm}^{-1}\right)$ (Supplementary Fig. 10) $)^{34,36}$. The occurrence of $v_{\text {as }}$ band $\left(1067 \mathrm{~cm}^{-1}\right)$ and $v_{\mathrm{s}}$ band $\left(980 \mathrm{~cm}^{-1}\right)$ of $-\mathrm{CS}_{2}$ of chelated perovskites reveals the bidentate nature of the dithiocarbamate moiety with slight geometrical distortion ${ }^{35,36}$. Compared with $\mathrm{Pb}(\mathrm{DDTC})_{2}$, the $v$ $(\mathrm{C}-\mathrm{N})$ and $v(\mathrm{C}-\mathrm{S})$ of the chelated $\mathrm{CsPbI}_{2} \mathrm{Br}$ perovskite shifted from 1481 and $904 \mathrm{~cm}^{-1}$ to 1497 and $910 \mathrm{~cm}^{-1}$, respectively, suggestive of the enhanced electron density near $\mathrm{C}-\mathrm{N}$ bond of DDTC molecule, which is also supported by the change of $\mathrm{Pb}-\mathrm{S}$ vibration peak (300-400 $\left.\mathrm{cm}^{-1}\right)$ from Raman spectra (Supplementary Fig. 11). Furthermore, ${ }^{13} \mathrm{C}-\mathrm{NMR}$ spectra in Supplementary Fig. 12 show that carbon signal of $-\mathrm{NCS}_{2}$ group of DDTC 
a

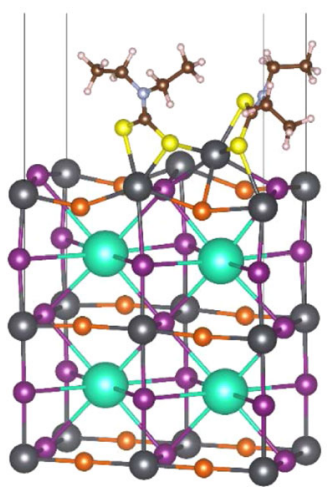

b

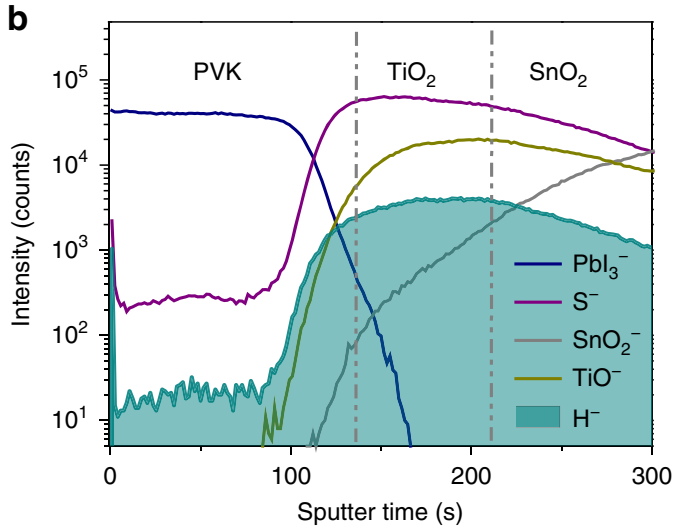

C

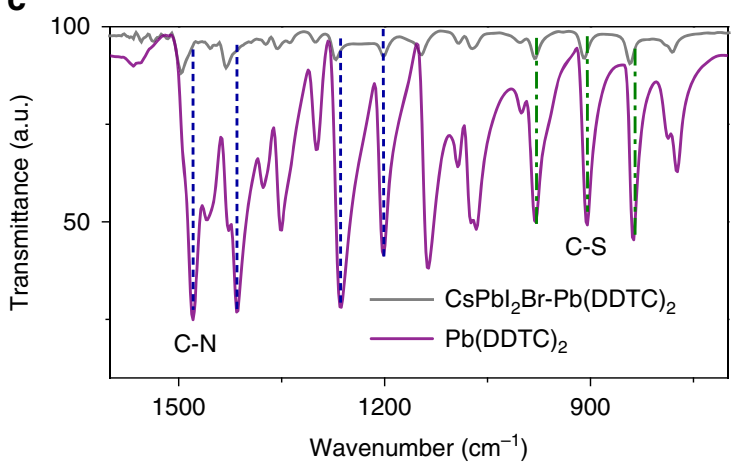

d

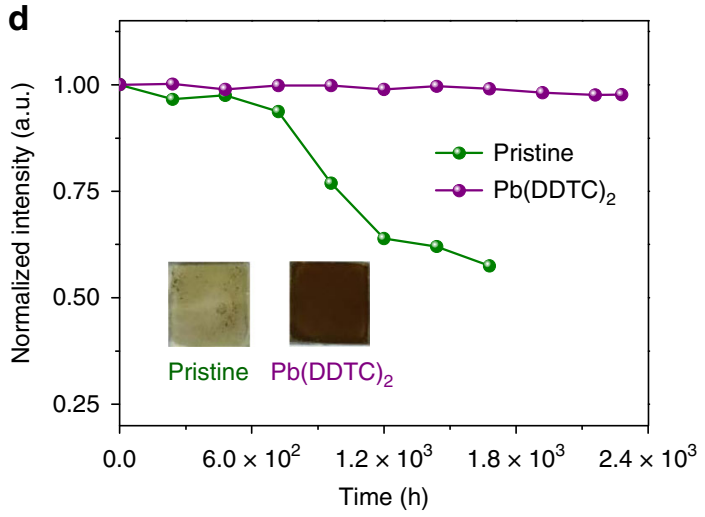

Fig. 1 Chelation characterization and moisture tolerance study. a Atomic structure of optimized $\mathrm{CsPb}_{2} \mathrm{Br}(001)$ surface with $\mathrm{Pb}(\mathrm{DDTC})_{2}$ molecule. b ToF-SIMS depth profile of the $\mathrm{CsPbl}_{2} \mathrm{Br}$ perovskite (PVK) film with $\mathrm{Pb}(\mathrm{DDTC})_{2}$ (chelated $\mathrm{CsPb}_{2} \mathrm{Br}$ ), measured in negative polarity. The measured film was structured as glass/FTO/c- $\mathrm{TiO}_{2} /$ perovskite. The concentration of $\mathrm{Pb}(\mathrm{DDTC})_{2}$ used for the chelated sample is $0.015 \mathrm{M}$. c FTIR spectra of Pb(DDTC) 2 (purple) and chelated $\mathrm{CsPb}_{2} \mathrm{Br}$ (gray) samples. The concentration of $\mathrm{Pb}(\mathrm{DDTC})_{2}$ and $\mathrm{CsPb}_{2} \mathrm{Br}$ perovskite in precursor solution are 0.02 and $1.0 \mathrm{M}$, respectively. $\mathrm{C}-\mathrm{N}$ stretching and $\mathrm{C}-\mathrm{S}$ stretching were highlighted by blue and green colored dotted line, respectively. $\mathbf{d}$ Evolution of normalized absorbance for pristine (green) and chelated (purple, $\left.\mathrm{Pb}(\mathrm{DDTC})_{2}\right) \mathrm{CsPbl}_{2} \mathrm{Br}$ thin films under dark in ambient atmosphere ( $\mathrm{RH}, 15 \pm 3 \%$ ). Absorption intensities at the wavelength of $400 \mathrm{~nm}$ were extracted from the UV-Vis absorption spectra of $\mathrm{CsPbl}_{2} \mathrm{Br}$ films. Insets are the photographs of pristine and chelated $\mathrm{CsPbl}{ }_{2} \mathrm{Br}$ films after exposure to ambient air for 70 and 95 days, respectively.

with $\mathrm{CsPbI}_{2} \mathrm{Br}$ shifted to high-field by $\Delta \delta=2.0 \mathrm{ppm}$ compared to that of pure $\mathrm{Pb}(\mathrm{DDTC})_{2}$, in consistent with FTIR and Raman results. This behavior might be stemmed from the electron donation from the extra unsaturated $\mathrm{Pb}$ sites of perovskite surface as suggested by the DFT simulation ${ }^{37-39}$. Orthogonal FTIR measurements further reveal the dependence of $\mathrm{C}-\mathrm{N}$ stretching of DDTC molecules on the targeted materials: $v(\mathrm{C}-\mathrm{N})$ of DDTC molecules with $\mathrm{CsI}, \mathrm{PbI}_{2}$ and $\mathrm{CsPbI}_{2} \mathrm{Br}$ are at 1481,1495 , and $1495 \mathrm{~cm}^{-1}$, respectively (Supplementary Fig. 13). The shift of $v$ $(\mathrm{C}-\mathrm{N})$ implies that the DDTC molecules mainly coordinate to $\mathrm{Pb}$ ions from $\mathrm{PbI}_{2}$ or perovskite, other than $\mathrm{Cs}$ ions from CsI that can be explained by Pearson acid-base concept, in good consistence with ${ }^{13} \mathrm{C}-\mathrm{NMR}$ results.

The surface chemical states of halides of perovskite were characterized by X-ray photoelectron spectroscopy (XPS). The I $3 d$ spectra exhibit two contributions, $3 d_{5 / 2}$ and $3 d_{3 / 2}$, located at 618.5 and $629.8 \mathrm{eV}$ for pristine film. The $\mathrm{Br} 3 d_{5 / 2}$ spectra exhibit two peaks at 68.4 and $69.4 \mathrm{eV}$, respectively (Supplementary Fig. 14$)^{40}$. Inclusion of $\mathrm{Pb}(\mathrm{DDTC})_{2}$ decreases the binding energies of $\mathrm{I} 3 d_{5 / 2}$ and $\mathrm{Br} 3 d_{5 / 2}$ to be 618.2 and $68.2 \mathrm{eV}$, respectively, which infers enhanced electron density around surface $\mathrm{Br} / \mathrm{I}$ species. This can be explained as the reduction of undercoordinated halide ions on perovskite surface through the interaction with the $\mathrm{Pb}$ cations in $\mathrm{Pb}(\mathrm{DDTC})_{2} 29,40$. The downshifted $\mathrm{Pb} 4 f$ peaks, as well as the emergence of and $\mathrm{S} 2 s$ peak of the chelated film, indicating the formation of $\mathrm{Pb}-\mathrm{DDTC}$ bonding at the surface ${ }^{15,28}$. Based on above structural and electronic properties combined with the theoretical results, we conclude that the DDTC molecules chelate surface $\mathrm{Pb}$ cations via a bidentate configuration to passivate surface unsaturated $\mathrm{Pb}$ sites. Moreover, the chemical bonding between surface chelated $\mathrm{Pb}$ cations and surface I/Br anions should be reinforced, which may further reduce the surface undercoordinated halide related defects ${ }^{37}$.

The $\mathrm{CsPb}_{2} \mathrm{Br}$ thin films with and without $\mathrm{Pb}(\mathrm{DDTC})_{2}$ were then stored in the ambient environment with relative humidity $(\mathrm{RH})$ of $15 \pm 3 \%$ for 95 days. The chelated $\mathrm{CsPbI}_{2} \mathrm{Br}$ film kept the original color over the entire tests, whereas the pristine one gradually turned yellow at $960 \mathrm{~h}$ (Supplementary Fig. 15). The $\mathrm{UV}-\mathrm{Vis}$ spectra present the stable light absorbance of the chelated film in ambient air over 95 days (Fig. 1d and Supplementary Fig. 14b). Furthermore, the water contact angles of $\mathrm{CsPb}_{2} \mathrm{Br}$ films increase from 42 to $76^{\circ}$ after chelation, which indicates the reduction of surface hydrophilicity by surface chelation (Supplementary Fig. 16).

Photovoltaic performance. The cross-sectional SEM image of the typical planar heterojunction solar cell device architecture of glass/fluorine-doped tin oxide (FTO)/compact $\mathrm{TiO}_{2}\left(\mathrm{c}-\mathrm{TiO}_{2}\right)$ / $\mathrm{CsPb}_{2} \mathrm{Br} / \mathrm{P} 3 \mathrm{HT} / \mathrm{Ag}$ is shown in Fig. 2a. The current densityvoltage $(J-V)$ curves of $\mathrm{CsPbI}_{2} \mathrm{Br}$ devices with different concentration of $\mathrm{Pb}(\mathrm{DDTC})_{2}$ measured under simulated $\mathrm{AM}$ 1.5G 
a
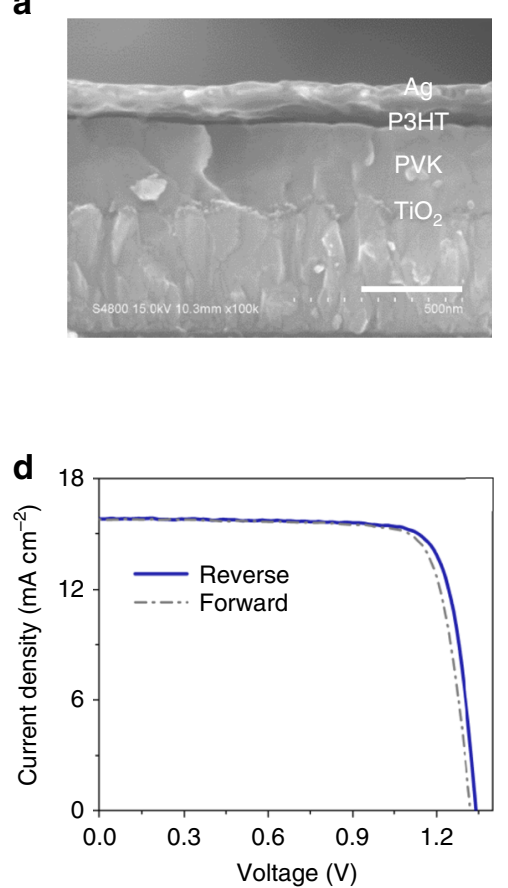
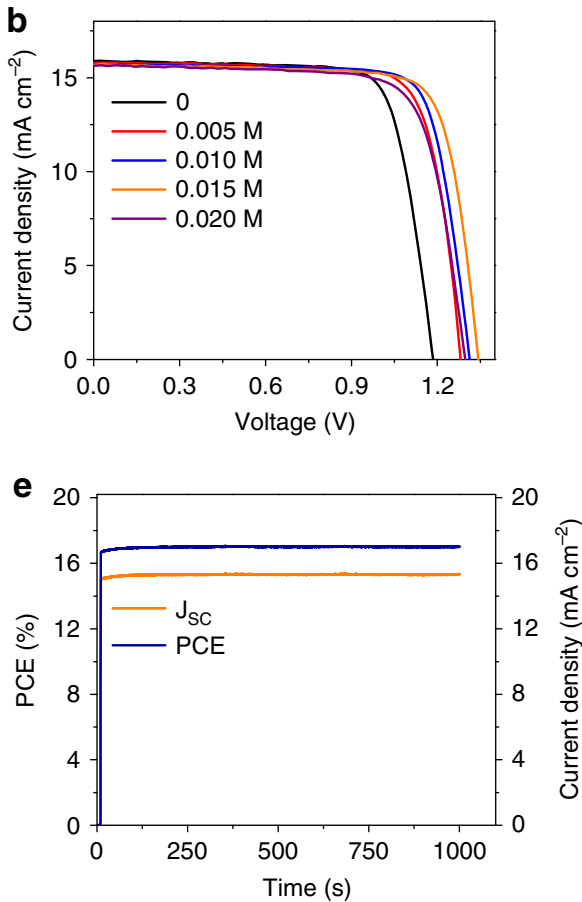
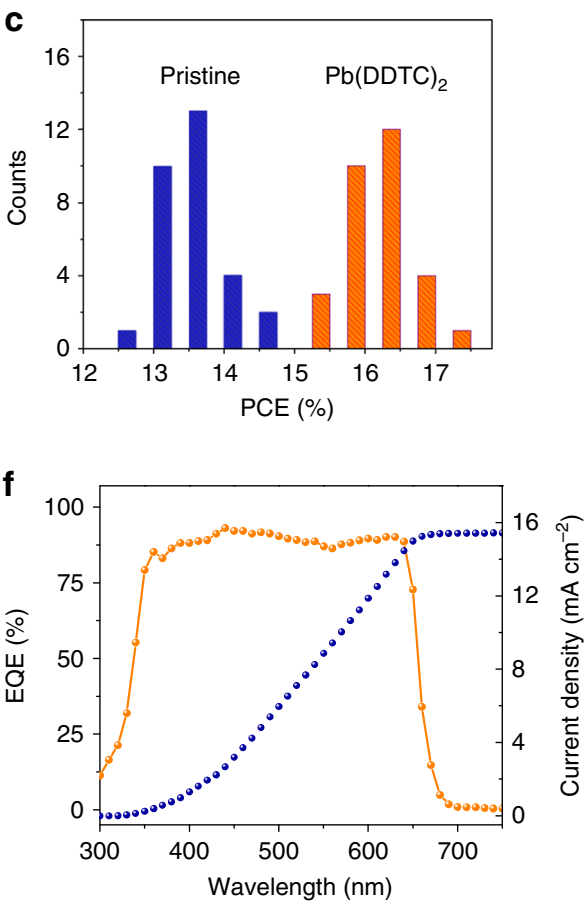

Fig. $2 \mathbf{C s P b}_{\mathbf{2}} \mathbf{B r}$ PSCs characterizations. a Cross-sectional SEM image of a chelated perovskite device. Scale bar is 300 nm. $\mathbf{b} J-V$ curves of perovskite solar cells with different concentrations of $\mathrm{Pb}(\mathrm{DDTC})_{2}$ under simulated $\mathrm{AM} 1.5 \mathrm{G}$ illumination $\left(100 \mathrm{~mW} \mathrm{~cm}^{-2}\right.$ ). c PCE histograms of pristine (blue) and chelated (orange) $\mathrm{CsPbl}_{2} \mathrm{Br}$ PSCs. d $J-V$ characteristics of the champion device for chelated $\mathrm{CsPbl}_{2} \mathrm{Br}$ solar cell at opposite scan directions. e Steady-state power output (blue) and current density (orange) of the champion cell measured at a fixed maximum power point (MPP) voltage (1.11 V) as a function of time. f EQE spectra (orange) and corresponding integrated photocurrent (blue) of the champion device.

illumination are shown in the Fig. 2b. The corresponding photovoltaic parameters are summarized in Supplementary Table 1. The pristine device delivered a short-circuit current density $\left(J_{\mathrm{SC}}\right)$ of $15.88 \mathrm{~mA} \mathrm{~cm}^{-2}$, an open-circuit voltage $\left(V_{\mathrm{OC}}\right)$ of $1.19 \mathrm{~V}$, a fill factor (FF) of $77.28 \%$ and a PCE of $14.54 \%$. The addition of $\mathrm{Pb}$ (DDTC $)_{2}$ mainly enhanced the $V_{\mathrm{OC}}$ of devices. The $V_{\mathrm{OC}}$ of the $\mathrm{CsPbI}_{2} \mathrm{Br}$ devices with $0.005,0.010,0.015$, and $0.020 \mathrm{M} \mathrm{Pb}$ $(\mathrm{DDTC})_{2}$ molecules were $1.28,1.31,1.34$, and $1.30 \mathrm{~V}$, generating high PCEs of $15.82 \%, 16.34 \%, 16.57 \%$, and $15.31 \%$, respectively. The reduction of PCE with excess $\mathrm{Pb}(\mathrm{DDTC})_{2}$ molecules can be explained by the large series resistance of insulating molecules. Given that $V_{\mathrm{OC}}$ are determined by quasi-Fermi level splitting under light irradiation, the chelated device should adopt much higher carrier concentration at open circuit probably because of the defect passivation effect of DDTC molecules. By using 0.015 $\mathrm{M} \mathrm{Pb}(\mathrm{DDTC})_{2}$, we improved the average PCE from $13.70 \pm$ $0.45 \%$ for pristine devices to $16.10 \pm 0.44 \%$ for chelated ones (Fig. 2c). The champion chelated device showed a $V_{\text {OC }}$ of $1.34 \mathrm{~V}$, a $J_{\mathrm{SC}}$ of $15.78 \mathrm{~mA} \mathrm{~cm}^{-2}$, and a FF of $80.52 \%$, generating a high PCE of $17.03 \%$ without notable hysteresis (Fig. $2 \mathrm{~d}$ and Supplementary Table 2). This champion device is among the best reported $\mathrm{CsPbI}_{2} \mathrm{Br}$ ones (Supplementary Table 3). Moreover, a record $V_{\mathrm{OC}}$ of $1.37 \mathrm{~V}$ for chelated $\mathrm{CsPbI}_{2} \mathrm{Br}$ cell was also attained with the $V_{\mathrm{OC}}$ deficit of about $0.51 \mathrm{eV}$ (Supplementary Fig. 17). The stabilized power output of champion device was recorded as $17.01 \%$ at maximum power point (MPP) under a bias of $1.11 \mathrm{~V}$, in conjunction with the stable $J_{\mathrm{SC}}$ of $15.32 \mathrm{~mA} \mathrm{~cm}^{-2}$ after $1000 \mathrm{~s}$ (Fig. 2e). The integrated current density $J_{\mathrm{SC}}$ value obtained from the external quantum efficiency (EQE) measurements carried out on this device was calculated to be $15.43 \mathrm{~mA} \mathrm{~cm}^{-2}$, well matches to that obtained from $J-V$ curve (Fig. 2f).

Steady-state photoluminescence (PL) and time-resolved PL (TRPL) measurements were operated, which are typical methods to assess the electronic passivation effect of chelating molecules on $\mathrm{CsPbI}_{2} \mathrm{Br}$ films ${ }^{4,29,41}$. As shown in Fig. 3a, the PL intensity of chelated film is enhanced to $\sim 2.1$ times larger than that of pristine one, indicating the suppression of nonradiative charge recombination $^{25}$. Meanwhile, the slight blue-shift of PL peak for the chelated film confirms the reduced shallow defects. TRPL spectra of both samples manifested a biexponential decay composed of a fast and a slow component that are typically assigned to charge trapping process and carrier recombination process, respectively (Fig. 3b $)^{23}$. The fast decay lifetime $\left(\tau_{1}\right)$ and slow decay lifetime $\left(\tau_{2}\right)$ are 11.1 and $68.2 \mathrm{~ns}$ for the pristine $\mathrm{CsPbI}_{2} \mathrm{Br}$ film, and 13.3 and $91.3 \mathrm{~ns}$ for the chelated one, respectively. The high PL intensity and prolonged lifetime of the chelated film are associated with the decrease of electronic trap density ${ }^{42}$. The lower dark current density of chelated device further indicates the reduction of shunt pathways, which may originate from the defective grain boundaries (Supplementary Fig. 18). To further evaluate the recombination behavior of the solar cell devices, the dependence of $V_{\mathrm{OC}}$ on light intensities was measured and the results were plotted as a function of light intensity in logarithm scales as shown in Fig. 3c. Ideality factor $(n)$ of the devices can be deduced by the slope of $V_{\mathrm{OC}}$ as a function of light intensity $(I)$ according to the following equation ${ }^{15}$ :

$$
V_{\mathrm{OC}}=\frac{E_{g}}{q}-\left(\frac{n k T}{q}\right) \ln \left(\frac{I_{0}}{I}\right),
$$

where $E_{\mathrm{g}}$ is the bandgap of light absorber, $k$ is the Boltzmann constant, $T$ is the absolute temperature, $q$ is the electron charge, and $I_{0}$ is a constant with the same unit as $I$. Figure $3 c$ shows the slopes of $1.76 \mathrm{kT} / \mathrm{q}$ for the chelated device and $2.22 \mathrm{kT} / \mathrm{q}$ for the pristine device, indicating the suppressed trap-induced recombination of the chelated device. Thermal admittance spectroscopy, as a well-established measurement of device trap density, was operated to measure the trap density of states (tDOS) of the 
a

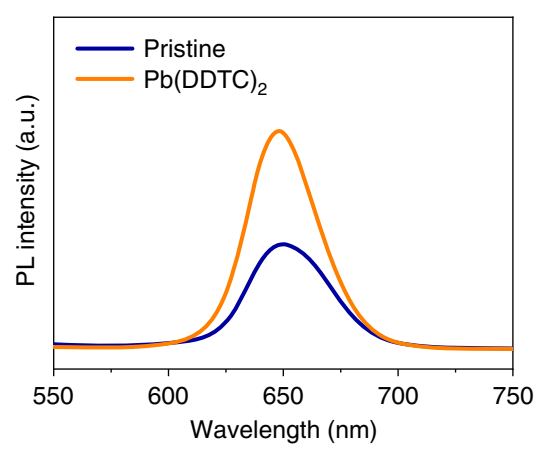

C

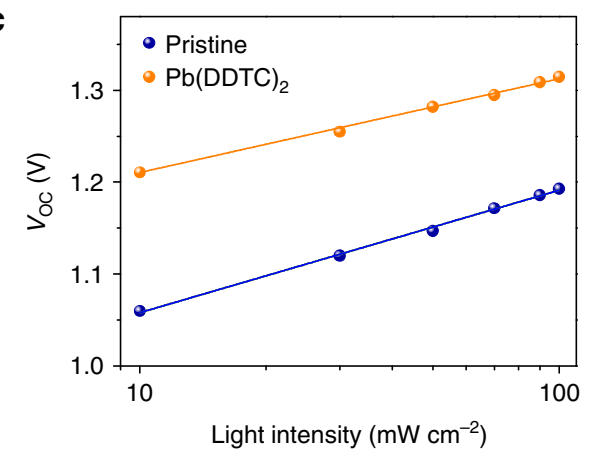

e

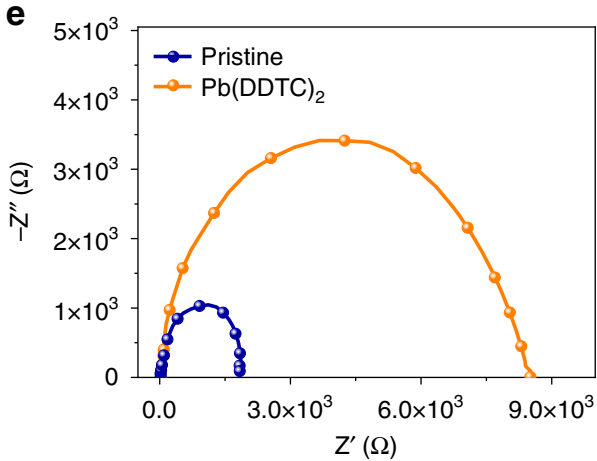

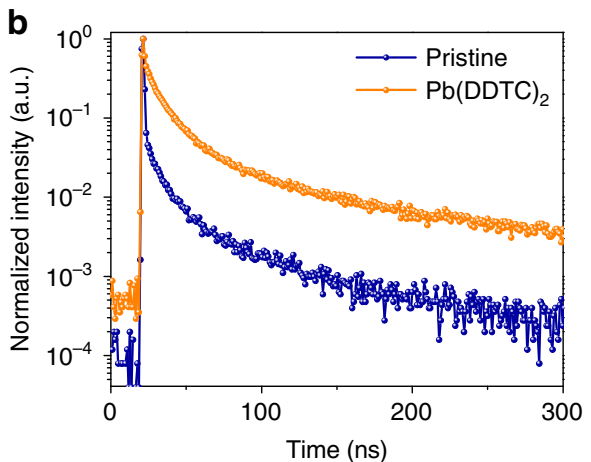

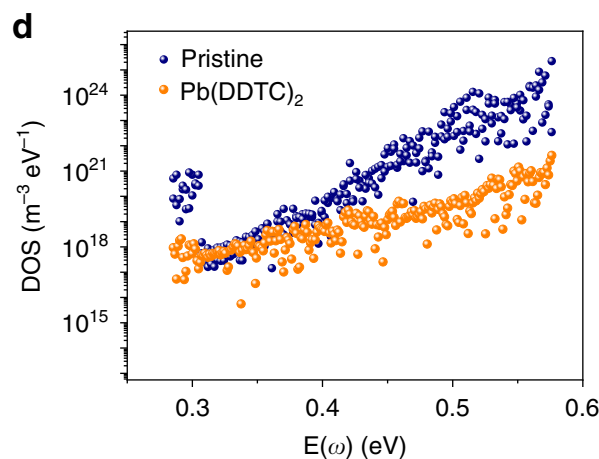

f

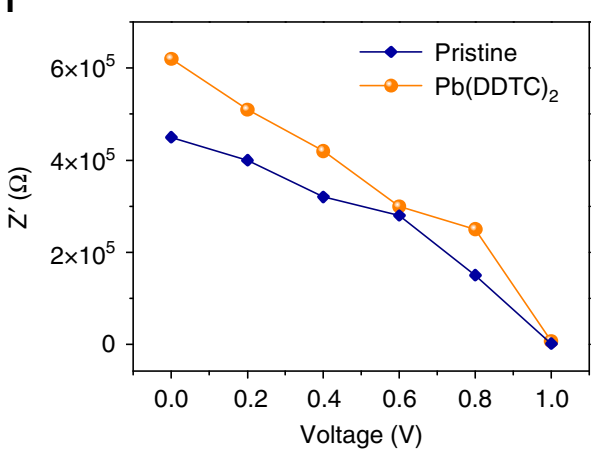

Fig. 3 Performance characterizations of $\mathbf{C s P b}_{\mathbf{2}} \mathbf{B r}$ films and solar cells. $\mathbf{a}, \mathbf{b}$ Steady-state PL and TRPL spectra, respectively, of the pristine (blue) and chelated (orange) $\mathrm{CsPb}_{2} \mathrm{Br}$ film deposited on glass substrate. c Plots of light intensity dependent $\mathrm{V}_{\mathrm{OC}}$ of the pristine (blue) and chelated (orange) $\mathrm{CsPb}{ }_{2} \mathrm{Br}$ devices. $\mathbf{d}$ tDOS of the pristine (blue) and chelated (orange) $\mathrm{CsPbl}_{2} \mathrm{Br}$ devices extracted from thermal admittance spectroscopy. e Nyquist plots of the pristine (blue) and chelated (orange) $\mathrm{CsPb}_{2} \mathrm{Br}$ devices under dark with a bias voltage of $1.0 \mathrm{~V}$. $\mathbf{f}$ Dependence of $R_{\text {rec }}$ on applied bias voltage for pristine (blue) and chelated (orange) $\mathrm{CsPbl}_{2} \mathrm{Br}$ device. $R_{\text {rec }}$ was obtained by fitting the EIS spectra at different voltages.

as-fabricated devices ${ }^{29}$. As evidenced by Fig. $3 \mathrm{~d}$, the tDOS of chelated device are more than ten times lower than the pristine one in the deep trap region (greater than $0.50 \mathrm{eV}$ ). We speculate that the DDTC molecule passivate the surface undercoordinated $\mathrm{Pb}$ and halide ions as discussed above. Electrochemical impedance spectroscopy (EIS) characterization was performed to further probe the carrier dynamics of $\mathrm{CsPb}_{2} \mathrm{Br}$ devices. The equivalent circuit model and fitting parameters of the impedance spectroscopy are showed in the Supplementary Fig. 1943,44. The recombination resistance $\left(R_{\text {rec }}\right)$ for the chelated device is about 4.3 times of that for pristine device at bias voltage of $1.0 \mathrm{~V}$ (Fig. 3e). The higher $R_{\text {rec }}$ of the chelated device under different bias voltages further represents the longer carrier lifetime of the chelated device, benefiting from the reduction of surface trap states (Fig. 3f) ${ }^{21,44}$.

Long-term device stability. Furthermore, the long-term stabilities of solar cell devices were tested under different conditions by adopting the device configuration of $\mathrm{FTO} / \mathrm{c}-\mathrm{TiO}_{2} /$ perovskite/ P3HT/Au. As given in Fig. 4a, the humid stability of chelated device was noticeably enhanced, maintaining over $98 \%$ of its original PCE under ambient conditions with $15 \pm 3 \%$ humidity for $1440 \mathrm{~h}$. In striking contrast, the pristine device only retained $53 \%$ of its initial efficiency within $840 \mathrm{~h}$ under the same conditions. The operational stability of $\mathrm{CsPb}_{2} \mathrm{Br}$ devices presented in Fig. $4 \mathrm{~b}$ indicated that there was only $11 \%$ efficiency drop for the chelated device after $520 \mathrm{~h}$ of continuous one-sun illumination in nitrogen atmosphere. As comparison, the pristine device lost $45 \%$ of its initial efficiency within $370 \mathrm{~h}$. Moreover, the chelated device showed a slow decrease of PCE over time and maintained $90 \%$ of its initial efficiency after $450 \mathrm{~h}$ at $85^{\circ} \mathrm{C}$, while the PCE value of the pristine $\mathrm{CsPbI}_{2} \mathrm{Br}$ device dropped dramatically to $57 \%$ for $360 \mathrm{~h}$ (Supplementary Fig. 20). Above results have verified the essential role of $\mathrm{Pb}(\mathrm{DDTC})_{2}$ that stabilize the perovskite device from the degradation. Ions migration has been proved to be as a possible origin of devices' intrinsic degradation under the working condition, which can be detected by PL emission under continuous 

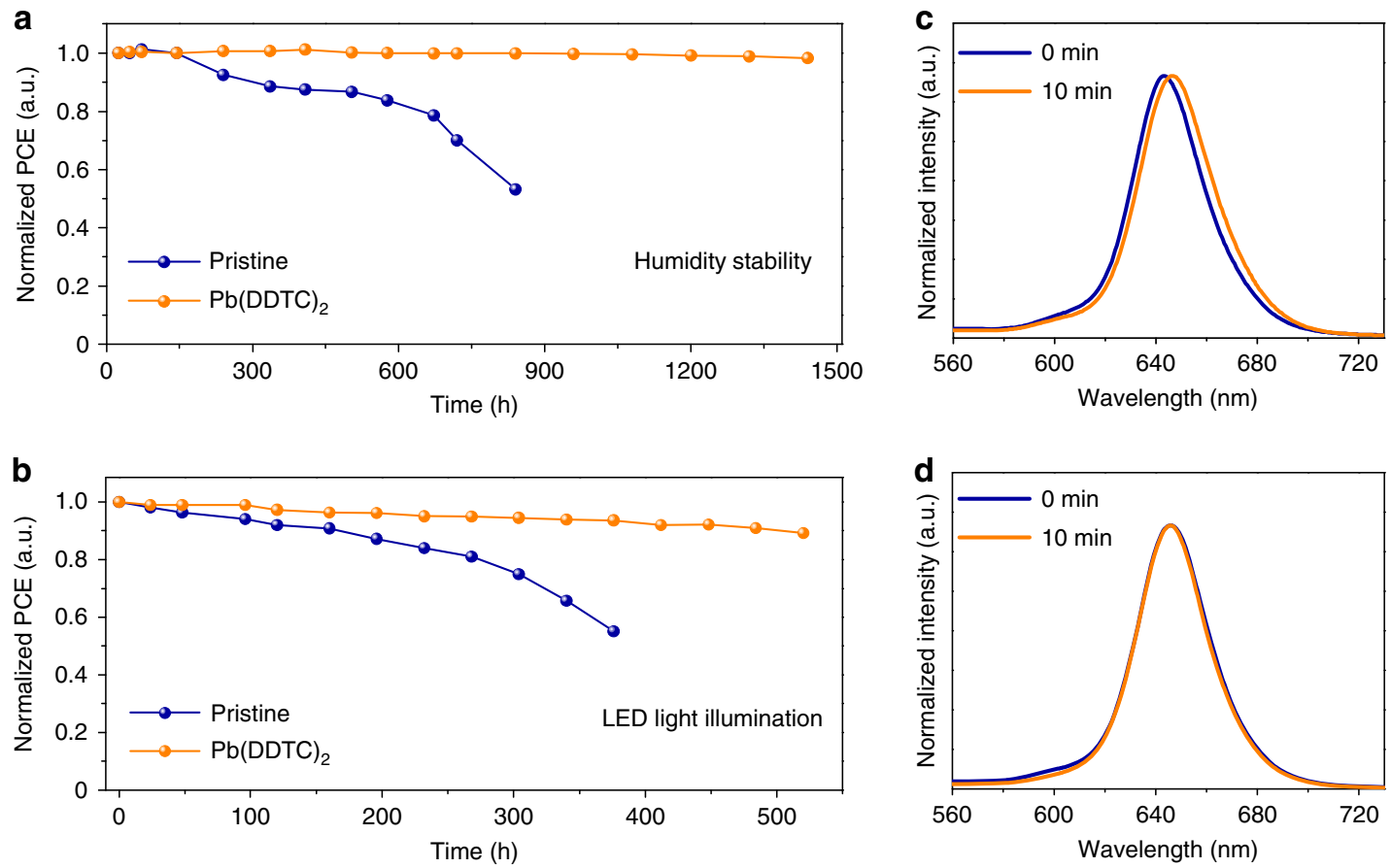

Fig. 4 Stability performance of PSCs. a Evolution of power conversion efficiency of the pristine (blue) and chelated (orange) $\mathrm{CsPb}{ }_{2} \mathrm{Br}$ devices without encapsulation. The devices were stored under ambient atmosphere with controlled humidity $(\mathrm{RH}, 15 \pm 3 \%$ ). b Long-term stability of the pristine (blue) and chelated (orange) devices under continuous $100 \mathrm{~mW} \mathrm{~cm}^{-2}$ white LED illumination in nitrogen glovebox. All devices configurations are $\mathrm{FTO}_{\mathrm{c}}-\mathrm{TiO}_{2} /$ perovskite/P3HT/Au. Normalized PL spectra of the (c) pristine and (d) chelated $\mathrm{CsPbl}_{2} \mathrm{Br}$ films under continuous one sun equivalent illumination for $10 \mathrm{~min}$. All perovskite films were deposited on glass substrates.

light irradiation ${ }^{15,26}$. The $\mathrm{PL}$ emission peak of pristine $\mathrm{CsPbI}_{2} \mathrm{Br}$ thin film had a red shift of about $3 \mathrm{~nm}$ under the continuous light illumination for $10 \mathrm{~min}$ (Fig. 4c). Encouragingly, we found that the chelated film displayed no change in PL emission, suggesting the suppressed ion migration after chelation (Fig. 4d).

\section{Discussion}

In summary, we have demonstrated the effectiveness of chelating molecular modulation on the surface property of perovskite films. Our experimental and theoretical results have elucidated the detailed surface chelation interactions of DDTC molecules to the surface $\mathrm{Pb}$ cations, which can passivate both undercoordinated surface $\mathrm{Pb}$ and $\mathrm{I} / \mathrm{Br}$ defects. The champion $\mathrm{PCE}$ and $V_{\mathrm{OC}}$ of chelated $\mathrm{CsPbI}_{2} \mathrm{Br}$ cells attained $17.03 \%$ and $1.37 \mathrm{~V}$, respectively, which are among the best reported results. Considering the strong adsorption of chelating molecules on perovskite, the stable bonding of chelating agents to the surface enables the long-term stability of perovskite devices. Other chelating agents, such as oxalic acid and ethylenediaminetetraacetic acid, were also tested with positive results. Our findings offer scientific avenues toward efficient and stable perovskite-based photovoltaic as well as other optoelectronic applications.

\section{Methods}

Materials and solution preparation. Lead nitrate $\left(\mathrm{Pb}\left(\mathrm{NO}_{3}\right)_{2}, 99 \%\right)$, ethanol $(\geq 99.7 \%)$ and sodium N,N-diethyldithiocarbamate trihydrate ( $\mathrm{NaDDTC} \cdot 3 \mathrm{H}_{2} \mathrm{O}$, 99\%) were purchased from Sinopharm Chemical Reagent Company. Lead bromide $\left(\mathrm{PbBr}_{2}, 99.9 \%\right)$, lead iodide $\left(\mathrm{PbI}_{2}, 99.9 \%\right)$, cesium iodide (CsI, 99.9\%), dimethyl sulfoxide (DMSO, anhydrous, $\geq 99.8 \%$ ), dimethyl sulfoxide- $d_{6}$ (DMSO- $d_{6}, \geq 99.9 \%$ ), chlorobenzene ( $\geq 99.9 \%)$, acetonitrile $(\geq 99.8 \%)$, 4-tert-butylpyridine (t-BP, $\geq 96.0 \%$ ), bis(trifluoromethane)sulfonimide lithium salt (Li-TFSI, $\geq 98.0 \%$ ) and titanium(IV) chloride $\left(\mathrm{TiCl}_{4},>98 \%\right)$ were purchased from Sigma-Aldrich. Poly (3methylthiophene) (P3HT) was purchased from Xi'an Polymer Light Technology Corp. All the chemicals and solvents were used as received without further purification. The $\mathrm{Pb}(\text { DDTC })_{2}$ was synthesized by adding $20.0 \mathrm{M} \mathrm{NaDDTC} \cdot 3 \mathrm{H}_{2} \mathrm{O}$ aqueous solution of $\mathrm{Pb}\left(\mathrm{NO}_{3}\right)_{2}$ aqueous solution $(10.0 \mathrm{M})$ dropwise under continuous magnetic stirring at room temperature. After stirring for $30 \mathrm{~min}$, the yellow precipitate was filtered and washed four times with pure water and dried in an oven at $60^{\circ} \mathrm{C}$. Firstly, $30.22 \mathrm{mg} \mathrm{Pb}(\mathrm{DDTC})_{2}$ was dissolved into $2.0 \mathrm{~mL}$ DMSO

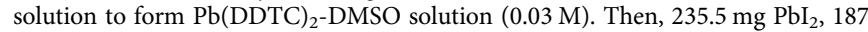
$\mathrm{mg} \mathrm{PbBr}_{2}$, and $272 \mathrm{mg} \mathrm{CsI}$ were dissolved in DMSO and $\mathrm{Pb}(\mathrm{DDTC})_{2}-\mathrm{DMSO}$ mixed solution to a final volume of $1 \mathrm{~mL}$ with desired $\mathrm{Pb}(\mathrm{DDTC})_{2}$ concentration, followed by stirring at room temperature overnight without filtration in a $\mathrm{N}_{2}$ glovebox.

Device fabrication and characterization. FTO substrate ( $8 \Omega$ per square, Nippon Sheet Glass) was sequentially cleaned with detergent, deionized water, acetone, and alcohol under sonication. Dry substrate was then immersed in a $25 \mathrm{mM} \mathrm{TiCl}_{4}$ aqueous solution for $60 \mathrm{~min}$ at $70^{\circ} \mathrm{C}$ and washed with deionized water and ethanol, followed by annealing at $500{ }^{\circ} \mathrm{C}$ for $60 \mathrm{~min}$ in muffle to form a c-TiO $\mathrm{T}_{2}$ blocking layer. The $\mathrm{CsPbI}_{2} \mathrm{Br}$ layer was fabricated by spin-coating the precursor solution on the $\mathrm{FTO} / \mathrm{c}-\mathrm{TiO}_{2}$ substrate via a two-step process with $500 \mathrm{rpm}$ for $3 \mathrm{~s}$, and 3500 rpm for $30 \mathrm{~s}$. Subsequently, these films were annealed at $43{ }^{\circ} \mathrm{C}$ for $2 \mathrm{~min}$, and then at $160^{\circ} \mathrm{C}$ for $10 \mathrm{~min}^{45}$. P3HT $(15 \mathrm{mg} / \mathrm{mL}$ in chlorobenzene, with $45 \mu \mathrm{L} \mathrm{Li}$-TFSI solution ( $2 \mathrm{mg}$ in $1 \mathrm{~mL}$ acetonitrile) and $10.2 \mu \mathrm{L} \mathrm{t}-\mathrm{BP}$ ) was spin-coated onto the $\mathrm{CsPbI}_{2} \mathrm{Br}$ perovskite film at $2500 \mathrm{rpm}$ for $25 \mathrm{~s}$ as a hole transporting layer. Finally, the device was finished by evaporating $\mathrm{Ag}$ or Au layers ${ }^{29}$.

FTIR spectroscopy, Raman spectroscopy (Raman) and Carbon-13 nuclear magnetic resonance $\left({ }^{13} \mathrm{C}-\mathrm{NMR}\right)$ were performed by FTIR Nicolet 6700 , Laser Raman InVia Reflex and Bruker Avance 500, respectively. The surface morphology and roughness of films were characterized by field emission scanning electron microscopy (HITACHI S4800) and atomic force microscopy (AFM, Veeco/DI). The XPS measurements were performed in ESCALAB 250Xi (Mg anode, $250 \mathrm{~W}$, $14 \mathrm{kV}$ ), and the binding energy of the $\mathrm{C} 1$ s peak at $284.8 \mathrm{eV}$ was taken as an internal pristine. XRD spectra of the prepared perovskite films were measured using powder X-ray diffraction (PXRD, Bruker Advance D8 X-ray diffractometer, $\mathrm{Cu}$ Ka radiation, $40 \mathrm{kV}$ ). Time-of-flight secondary-ion mass spectrometry (ToFSIMS VI, IONTOF GmbH, Muenster, Germany) elemental depth profiling was used to probing the distribution of elements. UV-Vis spectra were collected using a Cary 500 UV-Vis-NIR spectrophotometer in air ambient environments. The steady-state PL and TRPL spectra of perovskite films were acquired by Fluorolog-3p spectrophotometer and Endinburgh FLS890 spectrometer in air at room temperature, respectively. PL excitation wavelength was $380 \mathrm{~nm}$. Solar cells were illuminated by a solar light simulator (Solar IV-150A, Zolix) and light intensity was calibrated by a standard Newport calibrated KG5-filtered Si reference cell. The $J-V$ curves of devices were measured with Keithley 2400 digital sourcemeter under AM $1.5 \mathrm{G}$ irradiation $\left(100 \mathrm{~mW} \mathrm{~cm}^{-2}\right)$ at a scan rate of $0.15 \mathrm{~V} \mathrm{~s}^{-1}$ (voltages scan range: $0.3-1.5 \mathrm{~V}$, voltage step of $10 \mathrm{mV}$ ) in air ambient environments. Devices were 
masked with a metal aperture to define the active area to be $0.0625 \mathrm{~cm}^{2}$. The steady-state photocurrent output of the best-performing devices was measured by biasing the device at MPP in air ambient environments. EIS were measured out using an electrochemical workstation (Parstat 2273, Princeton) in the frequency range of $1 \mathrm{MHz}$ and $1 \mathrm{~Hz}$ under different positive bias voltages at dark conditions in air. The EQE was carried out on a Newport-74125 system (Newport Instruments) in air.

The $\mathrm{CsPb}_{2} \mathrm{Br}$ films and unsealed devices were stored in air ambient environments with $15 \pm 3 \%$ relatively humidity for long-term humidity test. White LED light illumination of $100 \mathrm{~mW} \mathrm{~cm}^{-2}$ for illumination stability tests of unencapsulated devices in nitrogen glovebox. The unencapsulated devices were baked on the hot plate at $85^{\circ} \mathrm{C}$ in nitrogen glovebox for thermal stability test.

Computational details. The first-principles DFT calculations were performed using the Vienna Ab initio Simulation Package code in this study ${ }^{46-48}$. The projector augmented wave method was used to describe the electron-ion interaction ${ }^{49}$, with valence electron structures of $5 s^{2} 5 p^{6} 6 s^{1}$ for Cs (Cs_sv), $5 d^{10} 6 s^{2} 6 p^{2}$ for $\mathrm{Pb}$ (Pb_d), $5 s^{2} 5 p^{5}$ for I, $4 s^{2} 4 p^{5}$ for Br, $3 s^{2} 3 p^{4}$ for S, $2 s^{2} 2 p^{2}$ for $\mathrm{C}, 2 s^{2} 2 p^{3}$ for $\mathrm{N}$, and $1 s^{1}$ for $\mathrm{H}$. The exchange and correlation effects of the electron-electron were described by using the Perdew-Burke-Ernzerhof (PBE) functional of a generalized gradient approximation method ${ }^{50}$. The plane-wave kinetic energy cutoff was set at $520 \mathrm{eV}$ to expand the smooth part of wave functions. All calculations were carried out on the thermodynamically stable $(001)$ surface using a $(1 \times 2)$ five-layer slab model with the periodic boundary condition. A vacuum region of $20 \AA$ was used to avoid the interaction between slabs. The Brillouin zone was sampled using Gamma-centered $(5 \times 3 \times 1) k$-point mesh for all surface calculations. Since traditional DFT calculations at the PBE level cannot correctly include the nonlocal van der Waals interactions, the calculations with dispersion corrections may affect the adsorption energies of small molecules ${ }^{51,52}$. In this regard, the DFT-D3 method was adopted for dispersion corrections here ${ }^{53}$. During the geometry optimizations, the bottom two layers were fixed at the bulk position, whereas the top three atomic layers and the adsorbents were fully relaxed with the energy and force convergences $<10^{-5} \mathrm{eV}$ and $0.01 \mathrm{eV} / \AA$, respectively.

The adsorption energy of each adsorbate $\left[\Delta E_{\mathrm{ad}}(\mathrm{eV})\right]$ was calculated as follows:

$$
\Delta E_{\mathrm{ad}}=E_{\mathrm{ad} / \mathrm{surf}}-E_{\text {surf }}-E_{\mathrm{ad}} .
$$

where $E_{\mathrm{ad}}, E_{\text {surf }}$, and $E_{\mathrm{ad} / \text { surf }}$ are the energies of an adsorbate, the clean (001) surface and the surface with adsorbates, respectively. For the calculations of adsorbate molecules, a $(20 \times 20 \times 20) \AA^{3}$ unit cell and a $\Gamma$-only $k$-point grid were used.

\section{Data availability}

The data that support the plots within this paper are available in separate Supplementary Source Data Files in Supplementary information section. All other relevant data are available from the corresponding authors upon reasonable request.

Received: 19 May 2020; Accepted: 1 August 2020;

Published online: 25 August 2020

\section{References}

1. Kojima, A., Teshima, K., Shirai, Y. \& Miyasaka, T. Organometal halide perovskites as visible-light sensitizers for photovoltaic cells. J. Am. Chem. Soc. 131, 6050-6051 (2009).

2. Kim, H.-S. et al. Lead iodide perovskite sensitized all-solid-state submicron thin film mesoscopic solar cell with efficiency exceeding 9\%. Sci. Rep. 2, 591 (2012).

3. Wehrenfennig, C., Eperon, G. E., Johnston, M. B., Snaith, H. J. \& Herz, L. M. High charge carrier mobilities and lifetimes in organolead trihalide perovskites. Adv. Mater. 26, 1584-1589 (2013).

4. Turren-Cruz, S.-H., Hagfeldt, A. \& Salibal, M. Methylammonium-free, highperformance, and stable perovskite solar cells on a planar architecture. Science 362, 449-453 (2018)

5. Song, J. et al. Monolayer and few-layer all-inorganic perovskites as a new family of two-dimensional semiconductors for printable optoelectronic devices. Adv. Mater. 28, 4861-4869 (2016).

6. Chen, Z. et al. Single-crystal $\mathrm{MAPbI}_{3}$ perovskite solar cells exceeding $21 \%$ power conversion efficiency. ACS Energy Lett. 4, 1258-1259 (2019).

7. Bryant, D. et al. Light and oxygen induced degradation limits the operational stability of methylammonium lead triiodide perovskite solar cells. Energy Environ. Sci. 9, 1655-1660 (2016).

8. Domanski, K. et al. Migration of cations induces reversible performance losses over day/night cycling in perovskite solar cells. Energy Environ. Sci. 10, 604-613 (2017).

9. Yang, S. et al. Functionalization of perovskite thin films with moisture-tolerant molecules. Nat. Energy 1, 15016 (2016).
10. Duan, J. et al. Carbon-electrode-tailored all-inorganic perovskite solar cells to harvest solar and water-vapor energy. Angew. Chem. Int. Ed. 57, 5746-5749 (2018).

11. Tian, J. et al. Dual interfacial design for efficient $\mathrm{CsPbI}_{2} \mathrm{Br}$ perovskite solar cells with improved photostability. Adv. Mater. 31, 1901152 (2019).

12. Zeng, Q. et al. Inorganic $\mathrm{CsPbI}_{2} \mathrm{Br}$ perovskite solar cells: the progress and perspective. Sol. RRL 3, 1800239 (2019).

13. Chen, W. et al. Precise control of crystal growth for highly efficient $\mathrm{CsPbI}_{2} \mathrm{Br}$ perovskite solar cells. Joule 3, 191-204 (2019).

14. Xiang, W. et al. Ba-induced phase segregation and band gap reduction in mixed-halide inorganic perovskite solar cells. Nat. Commun. 10, 4686 (2019).

15. Wang, J. et al. Highly efficient all-inorganic perovskite solar cells with suppressed non-radiative recombination by a Lewis base. Nat. Commun. 11, 177 (2020).

16. Yuan, Y. et al. Anomalous photovoltaic effect in organic-inorganic hybrid perovskite solar cells. Sci. Adv. 3, e16021642 (2017).

17. Fan, Z. et al. Layer-by-layer degradation of methylammonium lead tri-iodide perovskite microplates. Joule 1, 548-562 (2017)

18. Ball, J. M. \& Petrozza, A. Defects in perovskite-halides and their effects in solar cells. Nat. Energy 1, 16149 (2016).

19. Sherkar, T. S. et al. Recombination in perovskite solar cells: significance of grain boundaries, interface traps, and defect ions. ACS Energy Lett. 2, 1214-1222 (2017)

20. Kim, B., Kim, M., Lee, J. H. \& Seok, S. II Enhanced moisture stability by butyldimethylsulfonium cation in perovskite solar cells. Adv. Sci. 7, 1901840 (2019).

21. Wu, X. et al. Stable triple cation perovskite precursor for highly efficient perovskite solar cells enabled by interaction with 18C6 stabilizer. Adv. Funct. Mater. 30, 1908613 (2019).

22. Wang, Y. et al. Thermodynamically stabilized $\beta-\mathrm{CsPbI}$-based perovskite solar cells with efficiencies $>18 \%$. Science 365, 591-595 (2019).

23. Chen, $P$. et al. In situ growth of $2 \mathrm{D}$ perovskite capping layer for stable and efficient perovskite solar cells. Adv. Funct. Mater. 28, 1706923 (2018).

24. Zeng, Q. et al. Polymer-passivated inorganic cesium lead mixed-halide perovskites for stable and efficient solar cells with high open-circuit voltage over 1.3 V. Adv. Mater. 30, 1705393 (2018).

25. Zhang, Y. et al. High efficiency (16.37\%) of cesium bromide-passivated allinorganic $\mathrm{CsPbI}_{2} \mathrm{Br}$ perovskite solar cells. Sol. RRL 3, 1900254 (2019).

26. Shao, Y., Xiao, Z., Bi, C., Yuan, Y. \& Huang, J. Origin and elimination of photocurrent hysteresis by fullerene passivation in $\mathrm{CH}_{3} \mathrm{NH}_{3} \mathrm{PbI}_{3}$ planar heterojunction solar cells. Nat. Commun. 5, 5784 (2014).

27. Zhang, M. et al. Reconfiguration of interfacial energy band structure for high-performance inverted structure perovskite. Nat. Commun. 10, 4593 (2019).

28. Wang, R. et al. Constructive molecular configurations for surface-defect passivation of perovskite photovoltaics. Science 366, 1509-1513 (2019)

29. Yang, S. et al. Stabilizing halide perovskite surfaces for solar cell operation with wide-bandgap lead oxysalts. Science 365, 473-478 (2019).

30. Caruso, F., Chan, M.-L. \& Rossi, M. A short Pb...Pb separation in the polymeric compound bis-(pyrrolidinedithiocarbamato)lead(II) and a conformational pathway interconversion for the " $\mathrm{Pb}(\mathrm{II}) \mathrm{S}_{4}$ " framework. Inorg. Chem. 36, 3609-3615 (1997).

31. Hogarth, G. Metal-dithiocarbamate complexes: chemistry and biological activity. Mini-Rev. Med. Chem. 12, 1202-1215 (2012).

32. Kim, B., Kim, M., Lee, J. H. \& Seok, S. II Enhanced moisture stability by butyldimethylsulfonium cation in perovskite solar cells. Adv. Sci. 7, 1901840 (2019).

33. Zhang, L., Yu, F., Chen, L. \& Li, J. Adsorption of molecular additive onto lead halide perovskite surfaces: a computational study on Lewis base thiophene additive passivation. Appl. Surf. Sci. 443, 176-183 (2018).

34. Tiwari, S., Reddy, K. V., Bajpai, A., Khare, K. \& Nagaraju, V. Synthesis and characterization of bisdithiocarbamates from weak nitrogen bases and its metal complexes. Int. Res. J. Pure Appl. Chem. 7, 78-91 (2015).

35. Onwudiwe, D. C. \& Ajibade, P. A. Synthesis, characterization and thermal studies of $\mathrm{Zn}(\mathrm{II}), \mathrm{Cd}(\mathrm{II})$ and $\mathrm{Hg}(\mathrm{II})$ complexes of N-Methyl-NPhenyldithiocarbamate: the single crystal structure of $\left[\left(\mathrm{C}_{6} \mathrm{H}_{5}\right)\left(\mathrm{CH}_{3}\right)\right.$ $\left.\mathrm{NCS}_{2}\right]_{4} \mathrm{Hg}_{2}$. Int. J. Mol. Sci. 12, 1964-1978 (2011)

36. Sathiyaraj, E. \& Thirumaran, S. Synthesis and spectral studies on $\mathrm{Pb}$ (II) dithiocarbamate complexes containing benzyl and furfuryl groups and their use as precursors for PbS nanoparticles. Spectrochim. Acta Part A: Mole. Biomol. Spectrosc. 97, 575-581 (2012).

37. Zuo, L. et al. Polymer-modified halide perovskite films for efficient and stable planar heterojunction solar cells. Sci. Adv. 3, el700106 (2017).

38. Chen, B. et al. Imperfections and their passivation in halide perovskite solar cells. Chem. Soc. Rev. 48, 3842-3867 (2019).

39. Abate, A. et al. Supramolecular halogen bond passivation of organic-inorganic halide perovskite solar cells. Nano Lett. 14, 3247-3254 (2014). 
40. Subhani, W.S., Wang, K., Du, M., Wang, X. \& Liu, S. (Frank). Interfacemodification-induced gradient energy band for highly efficient $\mathrm{CsPbIBr}_{2}$ perovskite solar cells. Adv. Energy Mater. 9, 1803785 (2019).

41. Stranks, S. D. et al. Recombination kinetics in organic-inorganic perovskites: excitons, free Charge, and subgap states. Phys. Rev. Appl. 2, 034007 (2014).

42. Zhu, H. et al. Tailored amphiphilic molecular mitigators for stable perovskite solar cells with 23.5\% efficiency. Adv. Mater. 32, 1907757 (2020).

43. Ye, S. et al. A breakthrough efficiency of $19.9 \%$ obtained in inverted perovskite solar cells by using an efficient trap state passivator $\mathrm{Cu}$ (thiourea)I. J. Am. Chem. Soc. 139, 7504-7512 (2017).

44. Kim, H.-S. et al. High efficiency solid-state sensitized solar cell-based on submicrometer rutile $\mathrm{TiO}_{2}$ nanorod and $\mathrm{CH}_{3} \mathrm{NH}_{3} \mathrm{PbI}_{3}$ perovskite sensitizer. Nano Lett. 13, 2412-2417 (2013).

45. Liu, C. et al. All-inorganic $\mathrm{CsPbI}_{2} \mathrm{Br}$ perovskite solar cells with high efficiency exceeding 13\%. J. Am. Chem. Soc. 14, 3825-3828 (2018).

46. Kresse, G. \& Hafner, J. Ab initio molecular dynamics for open-shell transition metals. Phys. Rev. B 48, 13115-13118 (1993).

47. Kresse, G. \& Furthmüller, J. Efficiency of ab-initio total energy calculations for metals and semiconductors using a plane-wave basis set. Comput. Mater. Sci. 6, 15-50 (1996).

48. Kresse, G. \& Furthmüller, J. Efficient iterative schemes for ab initio totalenergy calculations using a plane-wave basis set. Phys. Rev. B 54, 11169-11186 (1996).

49. Kresse, G. \& Joubert, D. From ultrasoft pseudopotentials to the projector augmented-wave method. Phys. Rev. B 59, 1758-1775 (1999).

50. Perdew, J. P., Burke, K. \& Ernzerhof, M. Generalized gradient approximation made simple. Phys. Rev. Lett. 77, 3865-3868 (1996).

51. Klimeš, J. \& Michaelides, A. Perspective: advances and challenges in treating van der waals dispersion forces in density functional theory. J. Chem. Phys. 137, 120901 (2012).

52. Sun, T., Wang, Y., Zhang, H., Liu, P. \& Zhao, H. Adsorption and oxidation of oxalic acid on anatase $\mathrm{TiO}_{2}$ (001) surface: a density functional theory study. $J$. Colloid Interface Sci. 454, 180-186 (2015).

53. Grimme, S., Antony, J., Ehrlich, S. \& Krieg, H. A consistent and accurate ab initio parametrization of density functional dispersion correction (DFT-D) for the 94 elements H-Pu. J. Chem. Phys. 132, 154104 (2010).

\section{Acknowledgements}

This work was financially supported by National Natural Science Funds for Distinguished Young Scholar (51725201), National Natural Science Foundation of China (51972111, 51602103, 51902185), Young Elite Scientists Sponsorship Program by CAST (2017QNRC001), International (Regional) Cooperation and Exchange Projects of the National Natural Science Foundation of China (51920105003), Innovation Program of Shanghai Municipal Education Commission (E00014), the Fundamental Research Funds for the Central Universities (JKD012016025, JKD012016022), and Shanghai Engineering Research Center of Hierarchical Nanomaterials (18DZ2252400). This research was also undertaken on the supercomputers at the National Computational Infrastructure (NCI) in Canberra, Australia, which is supported by the Australian Commonwealth Government, and Pawsey Supercomputing Centre in Perth with funding from the Australian Government and the Government of Western Australia.

\section{Author contributions}

S.Y. and H.G.Y. directed the scientific research for this work. J.H. and S.Y. devised the idea of the project. J.H. performed the material preparation, device fabrication, and characterizations. Y.W. and J.L. conducted DFT calculations and wrote part of the paper (calculations). J.H. and S.Y. analyzed the data and prepared the paper with the help of Y.W. and H.Y. All the authors discussed the results and commented on the paper.

\section{Competing interests}

The authors declare no competing interests.

\section{Additional information}

Supplementary information is available for this paper at https://doi.org/10.1038/s41467020-18015-5.

Correspondence and requests for materials should be addressed to Y.H., Y.W. or S.Y.

Peer review information Nature Communications thanks Giulia Grancini and the other, anonymous, reviewer(s) for their contribution to the peer review of this work.

Reprints and permission information is available at http://www.nature.com/reprints

Publisher's note Springer Nature remains neutral with regard to jurisdictional claims in published maps and institutional affiliations.

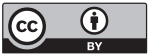

Open Access This article is licensed under a Creative Commons Attribution 4.0 International License, which permits use, sharing, adaptation, distribution and reproduction in any medium or format, as long as you give appropriate credit to the original author(s) and the source, provide a link to the Creative Commons license, and indicate if changes were made. The images or other third party material in this article are included in the article's Creative Commons license, unless indicated otherwise in a credit line to the material. If material is not included in the article's Creative Commons license and your intended use is not permitted by statutory regulation or exceeds the permitted use, you will need to obtain permission directly from the copyright holder. To view a copy of this license, visit http://creativecommons.org/ licenses/by/4.0/.

(C) The Author(s) 2020 